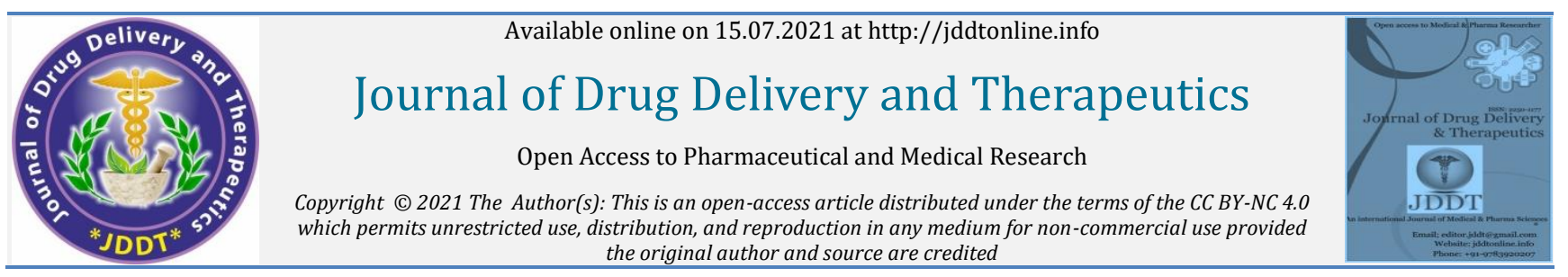

Open Access Full Text Article the original author and source are credited

Review Article

\title{
Agmatine: A potential Neurotherapeutic Agent
}

Binjhade Neha ${ }^{1}$, Supare Vinanti ${ }^{1}$, Ghaywat Shailesh ${ }^{1}$, Trivedi Sagar², (DWadher Kamlesh¹, Umekar Milind ${ }^{1}$

${ }^{1}$ Department of Pharmaceutics, Smt. Kishoritai Bhoyar College of Pharmacy, Kamptee, Nagpur, Maharashtra, India 441002

${ }^{2}$ Department of Pharmaceutics, Department of Pharmaceutical Sciences, Rashtrasant Tukadoji Maharaj Nagpur University Campus, Nagpur, India

\begin{tabular}{ll}
\hline Article Info: & \\
\hline$\square$ & Article History: \\
& $\begin{array}{l}\text { Received 12 May 2021 } \\
\text { Accepted 24 June 2021 }\end{array}$ \\
& Available online 15 July 2021 \\
\hline
\end{tabular}

Cite this article as:

Binjhade N, Supare V, Ghaywat S, Trivedi S, Wadher K, Umekar M, Agmatine: A potential Neurotherapeutic Agent, Journal of Drug Delivery and Therapeutics. 2021; 11(4):88-92

DOI: http://dx.doi.org/10.22270/jddt.v11i4.4855

*Address for Correspondence:

Dr. Kamlesh J. Wadher, Department of

Pharmaceutical Technology, Smt. Kishoritai Bhoyar

College of Pharmacy, Kamptee, Nagpur, Maharashtra, India 441002

ORCID ID: https://orcid.org/0000-0002-3782-3380

\section{Abstract}

Agmatine, a natural polyamine disregarded almost for over 100 years, was discovered in year 1910. Almost after a decade, several researches on Agmatine indicated its modulatory action at multiple molecular targets such as, nitric oxide synthesis, neurotransmitter systems, and polyamine metabolism unbolt the new avenues for extensive therapeutic applications which includes neurotrauma and neurodegenerative diseases, antidepressant, cognitive disorders. Agmatine exerts its varied biological characteristics and therapeutic potential in diverse arena. Agmatine has been extensively researched for its neuroprotective effect in various types of neurological diseases, including stroke and trauma brain injury along with Parkinson's disease, Alzheimer's disease, Hypoxia /Ischemia. In the present review we have summarized the therapeutic potential of agmatine as protective and regenerative properties in the CNS.

Keywords: Agmatine, Neuroprotective, Alzheimer's disease, Parkinson's disease, CNS disorders.

\subsection{Introduction}

Agmatine (AG), chemically know as 4-aminobutyl guanidine an endogenous amine, cationic in nature and has been known to be precursor for the synthesis of polyamines in plants and bacteria and mostly synthesized by decarboxylation of L- arginine by enzyme decarboxylase hence called decarboxylated arginine. ${ }^{1} \mathrm{AG}$ is widely distributed into mammalian tissues, particularly in stomach, small intestine, aorta and in lower level in spleen, adrenal gland, skeletal muscle, and brain. ${ }^{2}$. AG plays various pharmacological roles like processing cognitions, emotions, pain perception, including amygdala, septum, hypothalamus, nucleus, locus coeruleus, nucleusraphedorsalis, and periaqueductal gray. AG when administers systemically or centrally, it prevents or reverses opioid-induced tolerance, inflammatory and neuropathic pain associated with ischemia. AG alienates the N-methyl-D-aspartate receptor and inhibits nitricoxide synthase which demonstrated its effect in neural plasticity. ${ }^{3}$ Human agmatinase contains 352 amino acid residues and has a molecular weight of $37,688 \mathrm{kDa}$. It has $56 \%$ similarity to E. coli agmatinase and $42 \%$ similarity to human arginases I and II 4 This review deals with the various therapeutic potential of Agmatine and its action on various systems.
The therapeutic potential of AG in the various clinical manifestations has been depicted in figure 1 and table 1 .

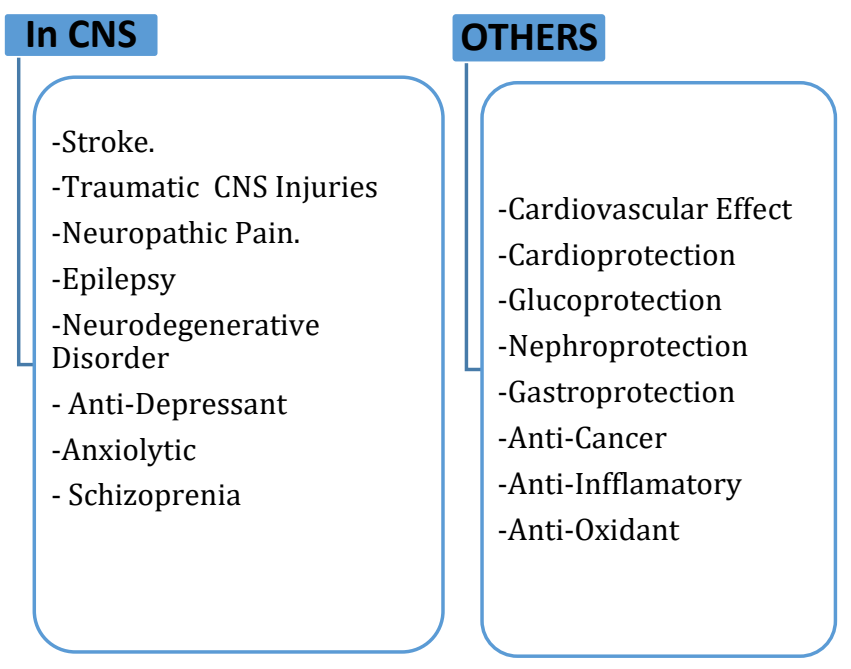

Figure 1: Therapeutic effect of agmatine 
Table 1: Therapeutic potential of agmatine in the various clinical manifestations

\begin{tabular}{|l|l|}
\hline Clinical manifestation & Comments \\
\hline Stroke. & Ameliorate BBB disruption. \\
\hline Traumatic CNS injuries. & Reduce astrocytic scar formation. \\
\hline Neuropathic pain. & Given orally and is available as a nutraceutical. \\
\hline Epilepsy & Several molecular targets related to neuroprotection. \\
\hline Neurodegenerative disorder. & In-vivo studies in Parkinson's disease model. \\
\hline Antidepressant properties. & Human biomarker studies \\
\hline Anxiolytic properties. & Involvement of increased endogenous agmatine metabolism. \\
\hline
\end{tabular}

\subsection{Neuroprotective effect of Agmatine}

AG has been found to exert neuroprotective effects in experimental models of neurotrauma and the identification of agmatine and its biosynthetic activity in mammalian brain it was hypothesized that agmatine might serve a neuroprotective role following neurotrauma. ${ }^{5}$

\subsection{Hypoxia /Ischemia (Stroke).}

Cerebral ischemia is a condition resulting from deprivation of oxygen and glucose that occurs mainly due impairing blood supply to specific brain regions. ${ }^{6}$. It leads to increased extracellular levels of glutamate causing, mitochondrial dysfunction, and oxidative stress. ${ }^{7}$. Literature suggests that agmatine is neuroprotective effect against transient focal or global cerebral ischemia and also increases astrocytes viability, rescuing these cells from death induced by in vitro oxygen-glucose deprivation model. ${ }^{8}$

\subsection{Traumatic brain injury (TBI) / Spinal cord injury (SCI).}

AG is an endogenous neuromodulator, significantly improves locomotor function and decreases tissue damage following traumatic SCI in rats. It also improve the locomotor activity in rats which, suggests that its importance to treatment of diseases related with nervous system 9,10 It is well recognized that the conjunction of acute and delayed events of TBI can lead to the development of psychiatric disorders, cognitive changes, seizures and epilepsy ${ }^{11 .} \mathrm{AG}$ found to improve regeneration of myelin sheath, protect the damaged neurons and gliosis, after SCI by increasing the expression of bone morphogenic protein and decreasing the expression transforming growth factor. ${ }^{11-12}$.

\subsection{Implications for epilepsy.}

Epilepsy is a neurologic disorder in which nervous system is disturbed by some activity causing seizures with severity increasing in accordance with age 13 . It has proven that $A G$ used to treat epilepsy, orally and intraperitoneally administered agmatine protected against maximal electroshock seizure (MES)-induced seizure 14. AG also potentiates the anticonvulsant effect of morphine or lithium chloride in mice through modulation on a2-adrenoceptors and enhances the anticonvulsant action of phenobarbital and valproate in the MES 15,16. AG showed to potentiate the anticonvulsant effects of melatonin and elicited anticonvulsant effect in MES and glutamate-induced seizure models in mice, the probable mechanism related to its ability to antagonize NMDA receptors 17,18 .

\subsection{Neurodegenerative Disorder.}

The neurodegenerative diseases are basically a progressive degeneration of neuronal systems due to neuro- inflammation, and oxidative stress that occurs due to increased production of reactive oxygen species and oxidative damage 19 as observed in Alzheimer and Parkinson's diseases. Many researcher reviewed about potential of AG as new pharmacological treatment for neurological and neurodegenerative diseases along with the molecular mechanisms underlying the neuroprotective effects. ${ }^{20}$

\subsubsection{Parkinson disorder (PD)}

PD is the second most common neurodegenerative disease which affects around 5\% of the population. It is a disease with complex etiology such as genetic risk factors, environmental factors and aging. 21. El-Sayed EK et al, investigated the neuroprotective effect of agmatine on a rotenone (ROT)-induced experimental model of PD and results showed that $A G$ possesses a neuroprotective effect through its antioxidant and anti-inflammatory activities. 22 AG treatment also showed neuroprotective in the mouse 1methyl-4-phenyl-1,2,3,6-tetrahydropyridine (MPTP) model of Parkinson's disease. ${ }^{23}$ Reinforcing the involvement of the glutaminergic system in PD, clinical and pre-clinical findings demonstrated the efficacy of memantine and amantadine, two NMDA receptor antagonists, in the treatment of PD 11,2428. Treatment with AG decreased cellular damage caused by rotenone through suppression of oxidative stress in a dosedependent manner. ${ }^{29}$. The safety and low incidence of adverse effects indicate the vast potential therapeutic value of agmatine in the treatment of neurological diseases. 30

\subsection{2-Alzheimer's disease (AD)}

Alzheimer's is a progressive disease that destroys memory and other mental functions and is the most common cause of dementia among older people. It has been reported in many literature that AG modulate cognitive functions, including learning and memory. ${ }^{31} \mathrm{AG}$ prevents hippocampal ERK and Akt inactivation induced by scopolamine, suggesting the role of AG against amnesia. 32,33. AG was also capable of protecting against Ab25-35-induced neuronal toxicity and memory deficits in a battery of behavioral tasks, including elevated plus maze, open field, memory version of the water maze task and object recognition memory task 34 . Additionally, AG administration reduced the accumulation of $\mathrm{Ab}$ and phosphorylated-tau in the brain, which may contribute to reduce cognitive decline in mice subjected to high-fat diet 35 .

\subsection{Effect of agmatine in Psychiatric disorder}

\subsection{Anxiety disorder.}

Anxiety is a mental health disorder relates with feeling of worry, fear, stress, obsessive compulsive disorder and posttraumatic stress disorder. AG showed marked effect on 
depression and anxiety like behaviour in mice through nitrergic pathway, which relates with modulation of oxidative-nitrergic stress and serum corticosterone levels. 36 AG reported as a potential therapeutic target in overcoming alcohol withdrawal symptoms such as anxiety and also causes a mild anxiolytic-like behavior in the elevated plus maze in rats 37,38 .

\subsection{Depression.}

Depression is a common and serious mood disorder with a high prevalence in the major population around the world 39. Kale $\mathrm{M}$ et. al, in their research work, project agmatine as a potential therapeutic target for type-II diabetes mellitus associated depression, anxiety, and co morbidities ${ }^{40}$. The antidepressant-like effect of AG seems to be also dependent on the modulation of other signaling pathways such as, increase in phosphorylation of protein kinase $\mathrm{A}$, protein kinase B/Akt, glycogen synthase kinase-3b and BDNF mediated signaling in the hippocampus ${ }^{41}$

\subsection{Schizophrenia}

Schizophrenia is commonly considered to be among the most intractable of mental illnesses and among the least comprehensible in terms of neurobiological mechanisms. ${ }^{42}$ Agmatine has been proposed to be a neuromodulator and the polyamines, have been suggested to be responsible for sensory gating deficits seen in schizophrenia. Several studies indicates the role of $\mathrm{AG}$ in the pathophysiology of schizophrenia band high levels of agmatine metabolites (spermine and spermidine) are found in the plasma, cerebrospinal fluid, and brain tissues of patients compared with healthy controls 43,44 .

\subsection{Cognitive enhancement: age-related changes and relevance to dementia}

Cognitive decline in biological aging is a known and cognitive enhancement therapy designed to help people with schizophrenia and related cognitive disorder improve brain and cognitive development, social cognition, and increase vocational capabilities. ${ }^{45}$. AG treatment reported to prevent endothelial dysfunction associated with vascular dementia through endothelial nitric oxide synthase and amygdaloid brain-derived neurotrophic factor expression in aged rats. 46.

\subsection{Effects of agmatine in learning and memory}

Learning and memory considered to be basic features of human activity that is our ability to think new ideas and to retain it in memory ${ }^{47}$. Results of the work carried out by Utkan $\mathrm{T}$ et al, indicates that $\mathrm{AG}$ has an important role in modulation of learning and memory functions. ${ }^{48}$ McKay BE et al, examined AG for its role in water maze place learning, fear learning. The results indicate that systemically administered AG selectively impairs behavioral inferences of specific types of learning and memory. ${ }^{49,50}$. A recent work investigated the levels of AG before, during and after the performance of the Morris water maze task. During the learning phase, the levels of AG found to increase by six times compared with the control group, suggesting that the endogenous AG system can be modulated during the learning process ${ }^{51}$.

\subsection{Anti-inflammatory effects}

Inflammation is a complex immune response of organisms to the injury. Under normal conditions, inflammation could help to scavenge the necrotic cells or tissues, and initiate the tissue repair process 52 . Inflammatory neurodegeneration contributes to a wide variety of brain pathologies. AG also reported to exert its anti-inflammatory effect by reducing the level of inflammatory cytokines, like tumor necrosis factor (TNF)- $\alpha$ and interleukins (IL)- $6{ }^{53}$. Kim JM et al investigated the anti-inflammatory effect of AG to reduce cerebral ischemic damage in diabetic rats. ${ }^{54}$.

\subsection{Antiapoptotic}

Apoptosis is one type of cell death characterized by energy dependence and programmed cell death 55. Zhu MY et al, demonstrated that AG can protect cultured hippocampal neurons from glucocorticoid induced neurotoxicity, via blocking of the N-methyl-D-aspartate receptor channels or a potential anti-apoptotic property. ${ }^{56}$. AG administration also prevent streptozotocin-induced memory deficit associated with hippocampal apoptosis 57. Ag reported to prevent apoptosis induced by TNF-a in retinal ganglion cells in vitro and LPS-induced hippocampal caspase-3 activation 58,59. The arginine metabolite agmatine protects mitochondrial function and confers resistance to cellular apoptosis. ${ }^{60}$. Some research findings indicates that $A G$ could overcome the nicotine evoked hepatic oxidative stress and tissue injury and apoptosis. 61,62 .

\subsection{Antioxidant}

AG has neuroprotective effects on retinal ganglion cells (RGCs) as well as cortical and spinal neurons. It protects RGCs from oxidative stress even when it is not present at the time of injury. ${ }^{63}$. Several studies have demonstrated the anti oxidative effect of AG in the setting of neurological diseases and it could ameliorate depressive like behavior by reducing the oxidative/nitrosative stress ${ }^{64}$ Ivanna Bila et al, in their research found that treatment with AG in diabetic animals repair redox homeostasis and a balances antioxidant defence system enzymes in leukocytes. 65

\section{Conclusion}

Agmatine, an endogenous polyamine is derived from arginine by decarboxylation process, is a neuromodulator that regulates multiple neurotransmitters and signaling pathways. A vast experimentation on agmatine demonstrates its neuroprotective activity and the treatment with agmatine could be new therapy for neurodegenerative diseases. The beneficial effect of agmatine reported in epilepsy and other neurodegenerative disorders including Alzheimer and Parkinson's disease. Agmatine also protects against inflammation, apoptosis and oxidative stress.

\section{Consent for Publication}

Not applicable.

\section{Conflict of Interest}

The authors declare no conflict of interest, financial or otherwise.

\section{REFERENCES}

1. Xu W, Gao L, Li T, Shao A, Zhang J. Neuroprotective role of agmatine in neurological diseases. Current neuropharmacology. 2018 Nov $1 ; 16(9): 1296-305$. https://doi.org/10.2174/1570159X15666170808120633

2. Otake K, Ruggiero DA, Regunathan S, Wang H, Milner TA, Reis DJ. Regional localization of agmatine in the rat brain: an immunocytochemical study. Brain research. 1998 Mar 16; 787(1):1-4. https://doi.org/10.1016/S0006-8993(97)01200-6

3. Wade CL, Eskridge LL, Nguyen HO, Kitto KF, Stone LS, Wilcox G, Fairbanks CA. Immunoneutralization of agmatine sensitizes mice to $\mu$-opioid receptor tolerance. Journal of Pharmacology and Experimental Therapeutics. 2009 Nov 1; 331(2):539-46. https://doi.org/10.1124/jpet.109.155424 
4. Iyer RK, Kim HK, Tsoa RW, Grody WW, Cederbaum SD. Cloning and characterization of human agmatinase. Molecular genetics and metabolism. 2002 Mar 1; 75(3):209-18. https://doi.org/10.1006/mgme.2001.3277

5. Laube, Gregor \& Bernstein, Hans-Gert. Agmatine: multifunctional arginine metabolite and magic bullet in clinical neuroscience?. Biochemical Journal. 2017; 474:2619-2640. https://doi.org/10.1042/BCJ20170007

6. Dirnagl U, Iadecola C, Moskowitz MA. Pathobiology of ischaemic stroke: an integrated view. Trends in neurosciences. 1999 Sep 1; 22(9):391-7. https://doi.org/10.1016/S0166-2236(99)01401-0

7. Kagaya K, Sasaki A, Kino Y, Taniguchi H, Kuraishi Y, Andoh T. Involvement of oxidative stress in increased peripheral nerve firing during spontaneous dysesthesia in a mouse model of ischemia-reperfusion. Neuroscience letters. 2016 Sep 19; 631:109-14. https://doi.org/10.1016/j.neulet.2016.08.034

8. Gilad GM, Gilad VH. Accelerated functional recovery and neuroprotection by agmatine after spinal cord ischemia in rats. Neuroscience letters. 2000 Dec 22; 296(2-3):97-100. https://doi.org/10.1016/S0304-3940(00)01625-6

9. Yu, Chen \& Marcillo, Alex \& Fairbanks, Carolyn \& Wilcox, George \& Yezierski, Robert. Agmatine improves locomotor function and reduces tissue damage following spinal cord injury. Neuroreport. 2000; 11: 3203-7. https://doi.org/10.1097/00001756-200009280-00031

10. Kjell, Jacob, and Lars Olson. Rat models of spinal cord injury: from pathology to potential therapies. Disease models \& mechanisms. 2016; 9(10):1125-1137. https://doi.org/10.1242/dmm.025833

11. Diamond B, Honig G, Mader S, Brimberg L, Volpe BT. Brainreactive antibodies and disease. Annu Rev Immunol. 2013; 31:345-385. https://doi.org/10.1146/annurev-immunol020711-075041

12. Kim JY, Lee YW, Kim JH, Lee WT, Park KA, Lee JE. Agmatine attenuates brain edema and apoptotic cell death after traumatic brain injury. Journal of Korean medical science. 2015l; 30(7):943. https://doi.org/10.3346/jkms.2015.30.7.943

13. England MJ, Liverman CT, Schultz AM, Strawbridge LM. A summary of the Institute of Medicine report: epilepsy across the spectrum: promoting health and understanding. Epilepsy \& behavior: E\&B. 2012 Oct; 25(2):266. https://doi.org/10.1016/j.yebeh.2012.06.016

14. Kaufman DM, Geyer HL, Milstein MJ. Kaufman's Clinical Neurology for Psychiatrists E-Book. Elsevier Health Sciences; 2016 Nov 28.

15. Bahremand A, Ziai P, Khodadad TK, Payandemehr B, Rahimian R, Ghasemi A, Ghasemi M, Hedayat T, Dehpour AR. Agmatine enhances the anticonvulsant effect of lithium chloride on pentylenetetrazole-induced seizures in mice: Involvement of Larginine/nitric oxide pathway. Epilepsy \& Behavior. 2010 Jul 1; 18(3):186-92. https://doi.org/10.1016/j.yebeh.2010.04.014

16. Luszczki JJ, Czernecki R, Wojtal K, Borowicz KK, Czuczwar SJ. Agmatine enhances the anticonvulsant action of phenobarbital and valproate in the mouse maximal electroshock seizure model. Journal of neural transmission. 2008 Nov; 115(11):1485-94. https://doi.org/10.1007/s00702-008-0046-3

17. Feng Y, LeBlanc MH, Regunathan S. Agmatine reduces extracellular glutamate during pentylenetetrazole-induced seizures in rat brain: a potential mechanism for the anticonvulsive effects. Neuroscience letters. 2005 Dec 30; 390(3):129-33. https://doi.org/10.1016/j.neulet.2005.08.008

18. Su RB, Wei XL, Zheng JQ, Liu Y, Lu XQ, Li J. Anticonvulsive effect of agmatine in mice. Pharmacology Biochemistry and Behavior. 2004 Feb 1; 77(2):345-9. https://doi.org/10.1016/j.pbb.2003.11.016

19. Chen Z, Zhong C. Oxidative stress in Alzheimer's disease. Neuroscience bulletin. 2014 Apr 1; 30(2):271-81. https://doi.org/10.1007/s12264-013-1423-y

20. Neis VB, Rosa PB, Olescowicz G, Rodrigues AL. Therapeutic potential of agmatine for CNS disorders. Neurochemistry international. 2017 Sep 1; 108:318-31. https://doi.org/10.1016/j.neuint.2017.05.006

21. Ross CA, Smith WW. Gene-environment interactions in Parkinson's disease. Parkinsonism \& related disorders. 2007 Jan 1;13:S309-15. https://doi.org/10.1016/S1353-8020(08)700221

22. El-Sayed EK, Ahmed A, Morsy EE, Nofal S. Neuroprotective effect of agmatine (decarboxylated l-arginine) against oxidative stress and neuroinflammation in rotenone model of Parkinson's disease. Hum Exp Toxicol. 2019 Feb; 38(2):173-184. https://doi.org/10.1177/0960327118788139

23. Gilad GM, Gilad VH, Finberg JP, Rabey JM. Neurochemical evidence for agmatine modulation of 1-methyl-4-phenyl-1, 2, 3, 6-tetrahydropyridine (MPTP) neurotoxicity. Neurochemical research. 2005 Jun; 30(6):713-9. https://doi.org/10.1007/s11064-005-6865-9

24. Xiao X, Wu ZC, Chou KC. A multi-label classifier for predicting the subcellular localization of gram-negative bacterial proteins with both single and multiple sites. PloS one. 2011 Jun 17; 6(6):e20592. https://doi.org/10.1371/journal.pone.0020592

25. Blanchet PJ, Konitsiotis S, Chase TN. Amantadine reduces levodopa-induced dyskinesias in parkinsonian monkeys. Movement disorders: official journal of the Movement Disorder Society. 1998 Sep; 13(5):798-802. https://doi.org/10.1002/mds.870130507

26. Aarsland D, Ballard C, Walker Z, Bostrom F, Alves G, Kossakowsk K, Leroi I, Pozo-Rodriguez F, Minthon L, Londos E. Memantine in patients with Parkinson's disease dementia or dementia with Lewy bodies: a double-blind, placebo-controlled, multicentre trial. The Lancet Neurology. 2009 Jul 1; 8(7):613-8. https://doi.org/10.1016/S1474-4422(09)70146-2

27. Emre M, Tsolaki M, Bonuccelli U, Destée A, Tolosa E, Kutzelnigg A, Ceballos-Baumann A, Zdravkovic S, Bladström A, Jones R, 11018 Study Investigators. Memantine for patients with Parkinson's disease dementia or dementia with Lewy bodies: a randomised, double-blind, placebo-controlled trial. The Lancet Neurology. 2010 Oct 1; 9(10):969-77 https://doi.org/10.1016/S1474-4422(10)70194-0

28. Kucheryanu VG, Kryzhanovskii GN. Effect of glutamate and antagonists of $\mathrm{N}$-methyl-D-aspartate receptors on experimental parkinsonian syndrome in rats. Bulletin of experimental biology and medicine. $2000 \mathrm{Jul}$; $130(1): 629-32$ https://doi.org/10.1007/BF02682089

29. Condello S, Currò M, Ferlazzo N, Caccamo D, Satriano J, Ientile R. Agmatine effects on mitochondrial membrane potential andNF- $\kappa \mathrm{B}$ activation protect against rotenone-induced cell damage in human neuronal-like SH-SY5Y cells. Journal of neurochemistry. $2011 \mathrm{Jan} ; 116(1): 67-75$ https://doi.org/10.1111/j.1471-4159.2010.07085.x

30. Akasaka, N., Fujiwara, S. The therapeutic and nutraceutical potential of agmatine, and its enhanced production using Aspergillus oryzae. Amino Acids 2020; 52:181-197. https://doi.org/10.1007/s00726-019-02720-7

31. Sirvanci-Yalabik, M., Sehirli, A. O., Utkan, T., \& Aricioglu, F. Agmatine, a metabolite of arginine, improves learning and memory in streptozotocin-induced Alzheimer's disease model in rats. Bulletin of Clinical Psychopharmacology, 2016; 26(4):34254. https://doi.org/10.5455/bcp.20161121125642

32. Moosavi M, Khales GY, Abbasi L, Zarifkar A, Rastegar K. Agmatine protects against scopolamine-induced water maze performance impairment and hippocampal ERK and Akt inactivation. Neuropharmacology. 2012 Apr; 62(5-6):2018-2023. https://doi.org/10.1016/j.neuropharm.2011.12.031

33. Potasiewicz A, Hołuj M, Kos T, Popik P, Arias HR, Nikiforuk A. 3 Furan-2-yl-Np-tolyl-acrylamide, a positive allosteric modulator of the $\alpha 7$ nicotinic receptor, reverses schizophrenia-like cognitive and social deficits in rats. Neuropharmacology. 2017 Feb 1; 113:188-97. https://doi.org/10.1016/j.neuropharm.2016.10.002

34. Bergin DH, Liu P. Agmatine protects against $\beta$-amyloid25-35induced memory impairments in the rat. Neuroscience. 2010 Aug 25; 169(2):794-811. https://doi.org/10.1016/j.neuroscience.2010.05.004

35. Kang S, Kim CH, Jung H, Kim E, Song HT, Lee JE. Agmatine ameliorates type 2 diabetes induced-Alzheimer's disease-like alterations in high-fat diet-fed mice via reactivation of blunted insulin signalling. Neuropharmacology. 2017 Feb 1; 113:467-79. https://doi.org/10.1016/j.neuropharm.2016.10.029

36. Goodwin GM. The overlap between anxiety, depression, and obsessive-compulsive disorder. Dialogues Clin Neurosci. 2015; 17(3):249-260. https://doi.org/10.31887/DCNS.2015.17.3/ggoodwin

37. Taksande BG, Kotagale NR, Patel MR, Shelkar GP, Ugale RR, Chopde CT. Agmatine, an endogenous imidazoline receptor ligand modulates ethanol anxiolysis and withdrawal anxiety in 
rats. European journal of pharmacology. 2010 Jul 10; 637(13):89-101. https://doi.org/10.1016/j.ejphar.2010.03.058

38. Lavinsky D, Arteni NS, Netto CA. Agmatine induces anxiolysis in the elevated plus maze task in adult rats. Behavioural brain research. 2003 Apr 17; 141(1):19-24. https://doi.org/10.1016/S0166-4328(02)00326-1

39. Wong ML, Licinio J. Research and treatment approaches to depression. Nature Reviews Neuroscience. 2001 May; 2(5):34351. https://doi.org/10.1038/35072566

40. Kale M, Nimje N, Aglawe MM, et al. Agmatine modulates anxiety and depression-like behaviour in diabetic insulin-resistant rats. Brain Research. 2020 Nov; 1747:147045. https://doi.org/10.1016/j.brainres.2020.147045

41. Freitas AE, Bettio LE, Neis VB, Santos DB, Ribeiro CM, Rosa PB, Farina M, Rodrigues AL. Agmatine abolishes restraint stressinduced depressive-like behavior and hippocampal antioxidant imbalance in mice. Progress in Neuro-Psychopharmacology and Biological Psychiatry. 2014 Apr 3; 50:143-50. https://doi.org/10.1016/j.pnpbp.2013.12.012

42. Casanova MF. Functional and anatomical aspects of prefrontal pathology in schizophrenia. Schizophrenia bulletin. 1997 Jan 1; 23(3):517-9. https://doi.org/10.1093/schbul/23.3.517

43. Uzbay T, Goktalay G, Kayir H, Eker SS, Sarandol A, Oral S, Buyukuysal L, Ulusoy G, Kirli S. Increased plasma agmatine levels in patients with schizophrenia. Journal of psychiatric research. 2013 Aug 1; 47(8):1054-60. https://doi.org/10.1016/j.jpsychires.2013.04.004

44. Das I, De Belleroche J, Essali MA, Richardson-Andrews RC, Hirsch SR. Blood polyamine in schizophrenia. Schizophrenia Research. 1989 Jan 1; 2(1-2):146. https://doi.org/10.1016/09209964(89)90182-5

45. Bağcı B, Utkan T, Yazir Y, Aricioglu F, Öztürk GS, Sarioglu Y. Effects of agmatine on cognitive functions during vascular dementia in biological aging through eNOS and BDNF expression. Psychiatry and Clinical Psychopharmacology. 2017 Apr 3; 27(2):106-15 https://doi.org/10.1080/24750573.2017.1309090

46. Rushaidhi M, Zhang H, Liu P. Effects of prolonged agmatine treatment in aged male Sprague-Dawley rats. Neuroscience. 2013 Mar 27; 234:116-24. https://doi.org/10.1016/j.neuroscience.2013.01.004

47. Kandel ER. The molecular biology of memory storage: a dialogue between genes and synapses. Science. 2001 Nov 2; 294(5544):1030-8. https://doi.org/10.1126/science.1067020

48. Utkan T, Gocmez SS, Regunathan S, Aricioglu F. Agmatine, a metabolite of L-arginine, reverses scopolamine-induced learning and memory impairment in rats. Pharmacol Biochem Behav. 2012 Oct; 102(4):578-84. https://doi.org/10.1016/j.pbb.2012.07.003

49. McKay BE, Lado WE, Martin LJ, Galic MA, Fournier NM. Learning and memory in agmatine-treated rats. Pharmacology Biochemistry and Behavior. 2002 Jun 1; 72(3):551-7. https://doi.org/10.1016/S0091-3057(02)00724-4

50. Seo S, Liu P, Leitch B. Spatial learning-induced accumulation of agmatine and glutamate at hippocampal CA1 synaptic terminals. Neuroscience. 2011 Sep 29; 192:28-36. https://doi.org/10.1016/j.neuroscience.2011.07.007

51. Rushaidhi M, Jing Y, Zhang H, Liu P. Participation of hippocampal agmatine in spatial learning: an in vivo microdialysis study. Neuropharmacology. 2013 Feb 1; 65:200-5. https://doi.org/10.1016/j.neuropharm.2012.10.007

52. Turrin NP, Rivest S. Molecular and cellular immune mediators of neuroprotection. Molecular neurobiology. 2006 Dec; 34(3):22142. https://doi.org/10.1385/MN:34:3:221
53. Taksande BG, Gawande DY, Chopde CT, Umekar MJ, Kotagale NR. Agmatine ameliorates adjuvant induced arthritis and inflammatory cachexia in rats. Biomedicine \& Pharmacotherapy. 2017 Feb 1; 86:271-8. https://doi.org/10.1016/j.biopha.2016.12.039

54. Kim JM, Lee JE, Cheon SY, Lee JH, Kim SY, Kam EH, Koo BN. The Anti-inflammatory Effects of Agmatine on Transient Focal Cerebral Ischemia in Diabetic Rats. J Neurosurg Anesthesiol. 2016 Jul; 28(3):203-13. https://doi.org/10.1097/ANA.0000000000000195

55. Elmore S. Apoptosis: a review of programmed cell death. Toxicologic pathology. 2007 Jun; 35(4):495-516 https://doi.org/10.1080/01926230701320337

56. Zhu MY, Wang WP, Bissette G. Neuroprotective effects of agmatine against cell damage caused by glucocorticoids in cultured rat hippocampal neurons. Neuroscience. 2006 Sep 15; 141(4):2019-27. https://doi.org/10.1016/j.neuroscience.2006.05.011

57. Moosavi M, Zarifkar AH, Farbood Y, Dianat M, Sarkaki A, Ghasemi R. Agmatine protects against intracerebroventricular streptozotocin-induced water maze memory deficit, hippocampal apoptosis and Akt/GSK3 $\beta$ signaling disruption. European journal of pharmacology. 2014 Aug 5; 736:107-14. https://doi.org/10.1016/j.ejphar.2014.03.041

58. Hong S, Lee JE, Kim CY, Seong GJ. Agmatine protects retinal ganglion cells from hypoxia-induced apoptosis in transformed rat retinal ganglion cell line. BMC neuroscience. $2007 \mathrm{Dec}$; 8(1):1-1. https://doi.org/10.1186/1471-2202-8-81

59. Hong, Samin \& Kim, Chan \& Lee, Jong Eun \& Seong, Gong. Agmatine protects cultured retinal ganglion cells from tumor necrosis factor-alpha-induced apoptosis. Life sciences. 2008; 84:28-32. https://doi.org/10.1016/j.lfs.2008.10.006

60. Arndt MA, Battaglia V, Parisi E, Lortie MJ, Isome M, Baskerville C, Pizzo DP, Ientile R, Colombatto S, Toninello A, Satriano J. The arginine metabolite agmatine protects mitochondrial function and confers resistance to cellular apoptosis. American Journal of Physiology-Cell Physiology. 2009 Jun; 296(6):C1411-9. https://doi.org/10.1152/ajpcell.00529.2008

61. Gardini G, Cabella C, Cravanzola C, Vargiu C, Belliardo S, Testore G, Solinas SP, Toninello A, Grillo MA, Colombatto S. Agmatine induces apoptosis in rat hepatocyte cultures. Journal of hepatology. 2001 Oct 1 ; 35(4):482-9. https://doi.org/10.1016/S0168-8278(01)00153-2

62. El-Sherbeeny NA, Nader MA, Attia GM, Ateyya H. Agmatine protects rat liver from nicotine-induced hepatic damage via antioxidative, antiapoptotic, and antifibrotic pathways. Naunyn Schmiedebergs Arch Pharmacol. 2016 Dec; 389(12):1341-1351. https://doi.org/10.1007/s00210-016-1284-9

63. Iizuka Y, Hong S, Kim CY, Yang WI, Lee JE, Seong GJ. Protective mechanism of agmatine pretreatment on RGC-5 cells injured by oxidative stress. Brazilian Journal of Medical and Biological Research. 2010 Apr; 43(4):356-8. https://doi.org/10.1590/S0100-879X2010007500018

64. Gawali NB, Bulani VD, Chowdhury AA, Deshpande PS, Nagmoti DM, Juvekar AR. Agmatine ameliorates lipopolysaccharide induced depressive-like behaviour in mice by targeting the underlying inflammatory and oxido-nitrosative mediators. Pharmacology Biochemistry and Behavior. 2016; 149:1-8. https://doi.org/10.1016/j.pbb.2016.07.004

65. Ivanna Bila, Olha Dzydzan, Iryna Brodyak, Natalia Sybirna. Agmatine prevents oxidative-nitrative stress in blood leukocytes under streptozotocin-induced diabetes mellitus" Open Life Sciences, 2019; 14(1):299-310. https://doi.org/10.1515/biol2019-0033 